\title{
INFLUENCE OF FALLS REDUCTION ON THE COST-EFFECTIVENESS OF ADVANCED HYDRAULIC MICROPROCESSOR CONTROLLED KNEE PROTHESES IN ELDERLY PATIENTS WITH LOWER LIMB AMPUTATIONS
}

\author{
Henning Krüger ${ }^{1}$, Andreas Hahn ${ }^{* 2}$, Alexander Kuhlmann ${ }^{3}$ \\ ${ }^{1}$ Leibniz University Hanover, Germany. \\ ${ }^{2}$ Otto Bock HealthCare, Vienna, Austria. \\ ${ }^{3}$ Center for Health Economics Research Hannover (CHERH), Hanover, Germany. \\ *E-Mail: andreas.hahn@ottobock.com
}

DOI: https://doi.org/10.33137/cpoj.v1i2.32041

\section{INTRODUCTION}

The assessment of cost-effectiveness and the use of health economical methods becomes of increasing importance when evaluating the impact of modern medical technology. The cost effectiveness of advanced hydraulic microprocessor controlled knees (MPKs) had recently by shown by RAND ${ }^{1}$. A new generation of advanced hydraulic microprocessor controlled knee (MPK) components became available to address specifically the needs of elderly individuals The reduction of concomitant factors such as falls may significantly improve cost-effectiveness.

\section{OBJECTIVE}

Aim of this investigation is to assess the cost effectiveness of advanced hydraulic MPKs vs. nonMPKs in a population of elderly above-knee amputees.

\section{METHODS}

A health economical decision tree based model was developed on the basis of existing clinical results ${ }^{2,3}$. The model population $(n=1.000$, transfemoral amputees, no gender specification) is of either vascular or non-vascular etiology and aged between 55 and 75 years. The incremental cost-effectiveness (ICER) is calculated to assess the economic efficiency of advanced hydraulic MPKs. Depending on the etiology and the chosen prosthetic fitting, the risk of falls, the number of falls, the severity of injuries and the injury related mortality are modeled over a five years horizon. Parameters related to costs and quality of live assessments are taken from the literature. To verify model assumptions and uncertainties in the chosen parameters a univariate analysis of the sensitivity is performed ${ }^{4}$.

\section{RESULTS}

The comparison of MPK and non-MPKs yields an ICER of 16.910 \$ per QALY for vascular and 19.848 \$ per QALY for non-vascular etiology. The largest impact on the model is due to the health utility values and prosthetic costs. The fatality avoidance rate is 7 fold increased in the vascular population.

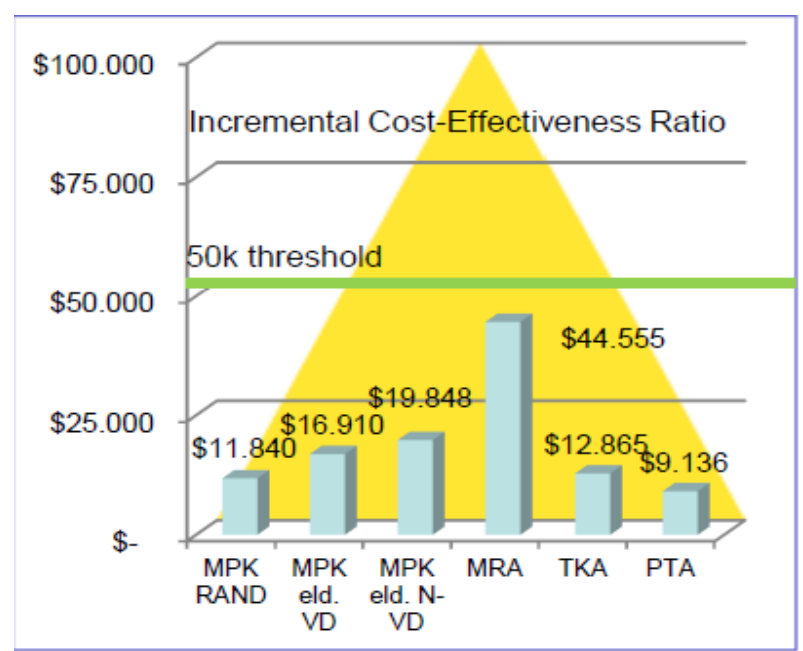

Figure 1. Comparison of ICER findings for elderly with RAND Results.

\section{CONCLUSION}

Results of the analysis indicate the cost-effectiveness of advanced hydraulic MPKs in elderly patients with lower limb amputation. We highlight the specific advantages fur subjects with vascular disease.

\section{SIGNIFICANCE}

Cost effectiveness of advanced hydraulic MPKs could also be shown in the population of elderly transfemoral amputees. Such findings may be supportive when 
arguing for successful coverage. Further need for research was identified.

\section{REFERENCES}

1. Liu et al., Economic Value of Advanced Transfemoral Prosthetics. Santa Monica, CA: RAND Corporation, 2017. https://www.rand.org/pubs/research_reports/RR2096.html.

2. Gerzeli S,Torbica A, Fattore G. Cost utility analysis of knee prosthesis with complete microprocessor control (C-leg) compared with mechanical technology in trans-femoral amputees. Eur J Health Econ. 2009 Feb;10(1):47-55. doi: 10.1007/s10198-008-0102-9. Epub 2008 Apr 1.

3. Seelen etal. Costs and consequences of a prosthesis with an electronically stance and swing phase controlled knee joint. Technol Disabil 2009;21(1-2):25-34. DOI: 10.3233/TAD2009-0269

4. Krüger, 2016, A Cost Estimation Model for the Extractive Software-Product-Line Approach. Master thesis, University of Magdeburg, Germany, February 2016. http://wwwiti.cs.unimagdeburg.de/iti_db/publikationen/ps/auto/thesisKrueger.pdf

\section{DISCLOSURE}

Krüger was M.Sc. of the Leibniz University Hanover. Hahn is full-time employee of Otto Bock HealthCare. Kuhlmann is Senior Research Associate at the CHERH of the University of Hanover. 